02

\title{
Изучение низкоэнергетических процессов в полиметилметакрилате и его короткоцепочечных олигомерах методом терагерцовой ИК и рамановской спектроскопии
}

\author{
(C) B.A. РЫжов \\ ФТИ им. А.Ф. Иофрфре РАН, \\ 194021 Санкт-Петербург, Россия \\ e-mail: v.ryzhov@mail.ioffe.ru
}

Поступила в редакцию 27.11.2018 г.

В окончательной редакции 02.09.2019 г.

Принята к публикации 03.09.19 г.

На основании данных низкочастотной (терагерцовой) ИК и рамановской спектроскопии установлено, что низкоэнергетические колебательные возбуждения в ПММА и его олигомерах со степенью полимеризации $n=2,7,9$ и 50 обусловлены малоугловой коррелированной крутильно-колебательной динамикой, подготавливающей релаксационную подвижность макромолекул. Определен минимальный размер участка цепи („,крутильно-колебательный сегмент“), спектр которого идентичен спектру высокомолекулярного полимера.

Ключевые слова: рамановская спектроскопия, низкоэнергетические колебательные возбуждения, релаксационная подвижность, олигомеры ПММА.

DOI: $10.21883 /$ OS.2019.12.48682.340-18

\section{Введение}

Аморфные полимеры, как известно, в зависимости от температурно-временной шкалы, на которой они исследуются, обнаруживают вязкоупругие свойства, определяемые молекулярной подвижностью с очень разной динамикой. При низких температурах или на коротких временах, когда молекулярная подвижность в основном локализована, макроскопическое механическое и диэлектрическое поведение аморфных полимеров проявляется в виде так называемых вторичных релаксаций.

Несмотря на большое число исследований, опубликованных по обнаружению вторичных релаксаций, вопрос об их происхождении все еще остается дискуссионным. Чаще всего в настоящее время проявление молекулярной подвижности в застеклованных полимерах связывают с низкоэнергетическими возбуждениями типа: малоугловой либрации звеньев цепи или молекул [1]; коррелированными колебаниями, проявляющимися как бозонный пик (БП) в ИК и рамановских спектрах [2], переориентационными процессами, проявляющихся как быстрые релаксационные явления [3].

Природа БП в настоящее время широко обсуждается. Ряд авторов полагает, что появление дополнительных квазилокальных колебательных мод связано с существованием в неупорядоченных средах среднего порядка и когезионной неоднородности [4]. Другие относят их к коррелированным колебаниям: например, в кварце крутильным колебаниям в цепочке из нескольких тетраэдров $\mathrm{SiO}_{4}[5]$.

В предыдущей работе [6] нами на основании сравнительного изучения ИК и рамановских спектров эти низкоэнергетические возбуждения в пластифицированном полиметилметакрилате (ПММА) были предположительно отнесены к либрационному движению в участках полимерной молекулы из нескольких мономерных звеньев. Целью настоящей работы является экспериментальная проверка этого предположения.

\section{Методика}

Образцы аморфного ПММА и его короткоцепочечных олигомеров со степенью полимеризации $n \cong 2,7,9$ и 50 синтезированы в ИХФ РАН методом каталитической передачи цепи на молекулу порфирина кобальта [7]. Все они, кроме димера, были приготовлены в виде пленок толщиной от 10 до $100 \mu \mathrm{m}$ для записи ИК спектров и в виде параллелепипедов с полированными гранями для получения рамановских спектров. Димер помещали в кювету с окнами из поли-4-метил-1-пентена, прозрачного на низких частотах. Измерения проводились при двух температурах: комнатной и температуре жидкого азота.

ИК спектры регистрировали на двух спектрометрах: в области от 10 до $50 \mathrm{~cm}^{-1}$ на спектрометре ЛГУ [8], модернизированном с помощью приемника ОАП-7 и новой системы фильтрации, а в диапазоне $50-130 \mathrm{~cm}^{-1}$ с использованием прибора FIS-21 Hitachi. Разрешение равнялось $1-2 \mathrm{~cm}^{-1}$. Погрешность определения положения максимума полос составляла $2-3 \mathrm{~cm}^{-1}$. Ошибка измерения коэффициента поглощения $k=\ln \left(J_{0} / J\right) /\left(t-t_{0}\right)$, где $J_{0}$ и $J$ - пропускание образцов толщиной $t_{0}$ и $t$ соответственно, составляла 5-10\%.

Рамановские спектры записывались на двойном монохроматоре Ramalog-5 по $90^{\circ}$-схеме рассеяния и были получены с помощью аргонового лазера с мощностью 
линии $488 \mathrm{~nm}$ порядка $0.1 \mathrm{~W}$. Спектральная ширина щели равнялась $2 \mathrm{~cm}^{-1}$. Зарегистрированные спектры $I(v)$, усредненные по 10 сканированиям в области $5-130 \mathrm{~cm}^{-1}$, нормировались с учетом спектральной функции прибора и частотного фактора рассеяния. Расчет низкочастотных рамановских спектров проводился путем преобразования полученных экспериментальных спектров по широко используемой формуле $[9,10]$ :

$$
I_{R}(v)=I(v)\left[1-\exp \left(\hbar v / k_{\mathrm{B}} T\right)\right]=I(v)[N(v)+1]^{-1},
$$

где $N(v)=\left[\exp \left(\hbar v / k_{\mathrm{B}} T\right)-1\right]^{-1}-$ бозе-фактор.

Представление рамановского спектра в координатах $I(v) /[N(v)+1]$ имеет то преимущество, что позволяет существенно уменьшить вклады упругой (рэлеевской) и релаксационной компонент крыла рассеяния. Кроме того, пересчитанные спектры непосредственно сравнимы со спектрами диэлектрических потерь $\varepsilon^{\prime \prime}(v)$. Поскольку на оптических частотах коэффициент поглощения $k$ пропорционален величине $v \varepsilon^{\prime \prime}(v)$, спектру $I(v) /[N(v)+1]$ отвечает и ИК спектр в координатах $k / v$. Пересчитанные таким образом рамановские и ИК спектры могут быть корректно сопоставлены друг с другом.

\section{Результаты и их обсуждение}

На рис. 1 представлены рамановские и ИК спектры ПММА и его олигомеров в диапазоне $10-150 \mathrm{~cm}^{-1}$ в координатах $I_{R}=I(v) /(N(v)+1)$ и $k / v$ соответственно. Они имеют типичный для низкочастотных спектров линейных аморфных полимеров вид широкой асимметричной полосы с максимумом при $80-90 \mathrm{~cm}^{-1}$ и изломом на частоте бозонного пика при $15-20 \mathrm{~cm}^{-1}$ [1].

Выполненные ранее исследования низкочастотных ИК спектров низкомолекулярных веществ и полимеров позволяют отнести рассматриваемую полосу к поглощению, обусловленному либрацией (вращательными колебаниями) мономерных звеньев в макромолекулах ПММА, т.е. к поглощению по механизму Поли [11].

К такому же движению следует отнести и обсуждаемую полосу в рамановском спектре ПММА, имеющую сопоставимый контур и близкое по частоте положение максимума [12].

Незначительное уширение полосы и сдвиг ее максимума в сторону низких частот в спектрах олигомеров, повидимому, вызваны увеличением амплитуды и ангармоничности либрационных колебаний в низкомолекулярных аналогах ПММА.

Идентичность механизмов формирования полос в низкочастотных ИК и рамановских спектрах конденсированных сред подтверждается многочисленными данными [13]. В одной из наиболее распространенных моделей, применяемых в настоящее время для анализа поглощения по механизму Поли [14], либрационное движение молекулы с моментом инерции (I) совершается в пределах образованной ее ближайшим окружением потенциальной ямы, имеющей форму $U(\phi)=U_{0} \sin ^{2} \pi \phi / 2 \xi$, с
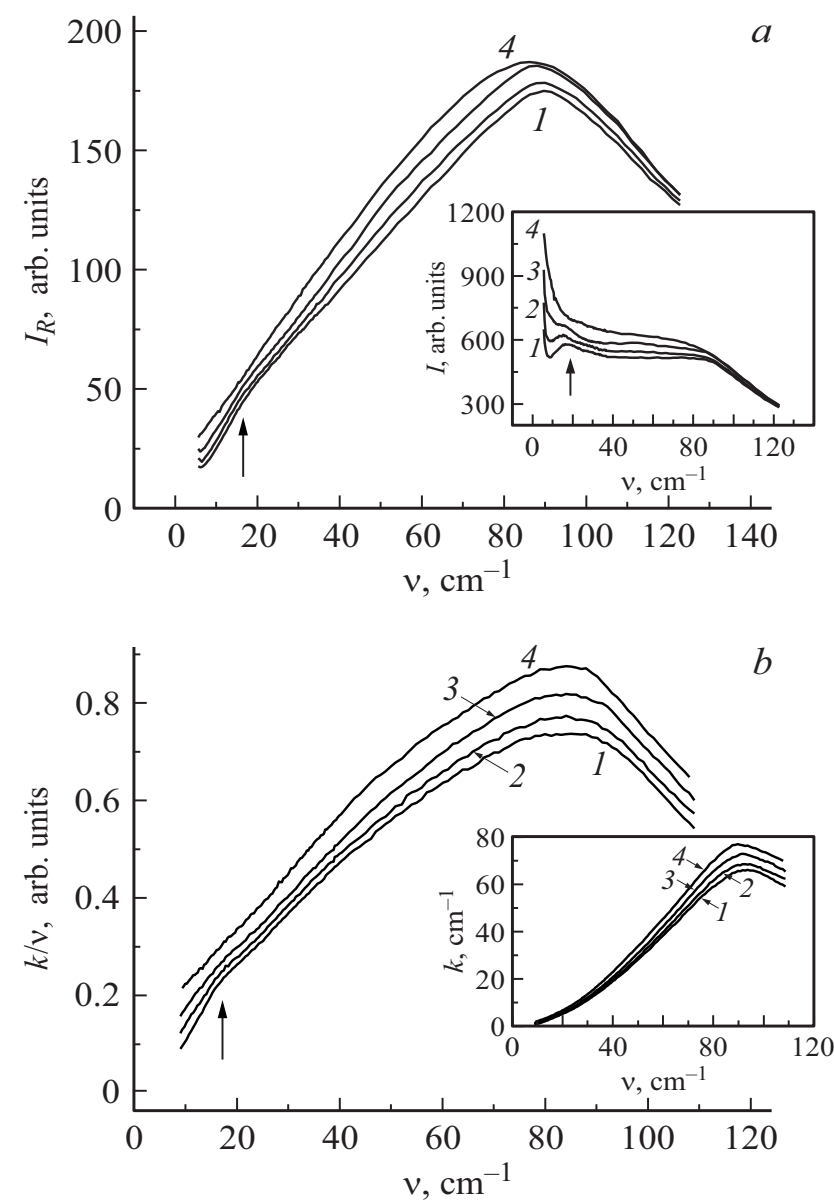

Рис. 1. Приведенные рамановские $(a)$ и ИК спектры $(b)$ в области $10-120 \mathrm{~cm}^{-1}$ исходного ПММА $(1)$ и его олигомеров с $n=9$ (2), 7 (3) и 2 (4). На вставках представлены их экспериментальные рамановские и ИК спектры на тех же частотах. Стрелки показывают положение бозонного пика в спектрах.

круговой частотой

$$
\omega=2 \pi c v_{\mathrm{libr}} \cong \pi / \xi\left(U_{0} / 2 I\right)^{1 / 2},
$$

где $U_{0}-$ глубина ямы, $\xi-$ ее полуугловая апертура (ширина на высоте, равной половине полного барьера), $\phi$ - амплитуда либрации.

Модель предсказывает положение максимума либрационной полосы в низкочастотных спектрах полярных и неполярных жидкостей. Найденные с еe помощью межмолекулярные барьеры либрационного движения соответствуют полученным другими методами [15].

Подобный подход для полимеров дает хорошее согласие с экспериментом при условии, что либрирующей единицей является мономерное звено макромолекулы. В таких расчетах принимается, что либратор имеет форму шара с моментом инерции $I=2 M R^{2} / 5$, где $M$ его молекулярная масса, а $R$ - эквивалентный радиус.

В случае ПММА оценка размеров либратора по $v_{\text {libr }}=95 \mathrm{~cm}^{-1}$ в выражении (1), исходящая из энергии 




Рис. 2. Приведенные ИК спектры ПММА $(1,2)$, олигомеров с $n=9(3,4), 7(5,6)$ и $2(7,8)$ при $T=90 \quad(1,3,5,7)$ и $293 \mathrm{~K}(2,4,6,8)$ в диапазоне $10-40 \mathrm{~cm}^{-1}$. Спектры олигомеров смещены по оси ординат.

активации $\delta$-перехода [16] и наличия в макромолекулах ограниченных крутильных колебаний с амплитудой $10^{\circ}-15^{\circ}$ [17], дает величину $R=0.25 \mathrm{~nm}$, что близко к ван-дер-ваальсову радиусу мономерного звена этого полимера.

Полученный результат является дополнительным аргументом в пользу отнесения полосы с максимумом при $95 \mathrm{~cm}^{-1}$ в низкочастотных рамановских и ИК спектрах ПММА и его олигомеров к либрационному движению мономерного звена макромолекулы.

Обратимся к другой особенности низкочастотных ИК и рамановских спектров ПММА и его олигомеров перегибу на низкочастотном крыле изучаемой полосы. В исходном (экспериментальном) рамановском спектре ПММА частота максимума бозонного пика $v_{B P}$ имеет значение $16-18 \mathrm{~cm}^{-1}[9,18]$. После „приведения“ экспериментального спектра в координаты $I(v) / N(v)+1$ бозонный пик трансформируется в перегиб на низкочастотном крыле полосы на той же частоте - $v_{B P}$ (рис. 1,a).

При сравнения приведенных рамановских спектров с приведенными в координаты $k(v) / v$ ИК спектрами (рис. $1, b)$ видно, что в перестроенных ИК спектрах ПММА на частоте бозонного пика $v_{B P} \cong 16-20 \mathrm{~cm}^{-1}$ также наблюдается аналогичный перегиб.

С целью выяснения молекулярной природы перегиба на низкочастотном крыле либрационной полосы рассмотрим приведенные ИК и рамановские спектры ПММА и его олигомеров (рис. 1 и 2). Из них следует, что с увеличением длины цепи перегиб на спектральной кривой смещается в сторону низких частот. Зависимость его положения - $v_{B P}$ от длины цепи олигомера, выраженной числом мономерных звеньев $n$, представлена на рис. 3. На эту же зависимость ложится и частота основного максимума полосы, обусловленной либрацией одного мономерного звена.

Это свидельствует о том, что перегиб на низкочастотном крыле основной полосы тоже характеризует либрационное движение, которое, как показывает зависимость $v_{B P}$ от $n$, следует отнести к движению, в котором участвует несколько мономерных звеньев. График на рис. 3 позволяет оценить максимальное число звеньев цепи, вовлеченных в это коррелированное либрационное движение. В случае ПММА и его олигомеров оно не превышает 5-7 мономеров.

Длин $L$ такого участка основной цепи можно также определить, используя следующее выражение [9]:

$$
L \approx c_{t}\left(c v_{\mathrm{BP}}\right)^{-1}
$$

где $c$ - скорость света в вакууме, $c_{t}-$,поперечная“ скорость звука (скорость сдвиговой волны). Для ПММА $c_{t} \cong 1.42 \mathrm{~km} / \mathrm{s}$ [18]. Подставив в (2) это значение и значение частоты бозонного пика $v_{B P}=17 \mathrm{~cm}^{-1}$, находим, что в ПММА $L \cong 3 \mathrm{~nm}$. Полученная величина отвечает длине участка полимерной цепи из шести мономерных звеньев и близка к размеру статистического сегмента Куна для ПММА [19]. Сегмент характеризует в данном случае динамическую взаимосвязь соседних звеньев в полимерной цепи.

Если в выражение (2) подставить значение частоты максимума либрационной полосы $v_{\mathrm{libr}}=95 \mathrm{~cm}^{-1}$, то найденное значение длины участка полимерной молекулы оказывается равным $0.5 \mathrm{~nm}$, т.е. длине мономерного звена в ПММА.

Итак, широкая полоса в низкочастотных ИК и рамановских спектрах ПММА и его олигомеров с максимумом при $95 \mathrm{~cm}^{-1}$ характеризует крутильные колебания мономерного звена полимера, тогда как перегиб на ее

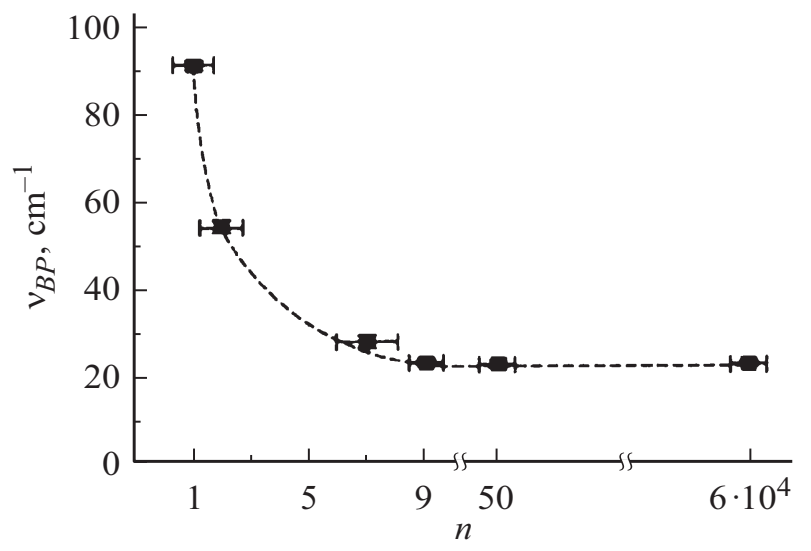

Рис. 3. Зависимость $v_{B P}$ от степени полимеризации, выраженной числом мономерных звеньев $n$. 
низкочастотном крыле при $16-18 \mathrm{~cm}^{-1}$ обусловлен коррелированными крутильными колебаниями с участием нескольких мономерных звеньев.

Примечательно, что линейные размеры области коллективных колебательных возбуждений и в других стеклообразных полимерах сопоставимы с размерами их статистических сегментов. Так, из анализа рамановских спектров стеклообразного полистирола (ПС) и его олигомеров $[20,21]$ следует, что размер указанной области здесь составляет 6-8 мономерных звеньев (статистический сегмент ПС равен 8 звеньям [19]). Для полибутадиена [21] и полипропиленгликоля [22] область коллективных колебательных возбуждений включает соответственно 11 и 7 мономерных звеньев, что также близко к величинам статистических сегментов для этих полимеров.

Существенно и то, что найденный из частоты $v_{B P}$ в низкочастотных ИК и рамановских спектрах линейный размер области коррелированных либрационных возбуждений близок к минимальному фрагменту полимерной цепи, необходимому для осуществления в ней поворотно-изомерного перехода. Движение участков такой длины, совершающееся в местах наименее плотной упаковки макромолекул, лежит в основе $\beta$ релаксации $[19,23]$. Оно является аналогом релаксации Джохари-Гольдштейна [24] в низкомолекулярных застеклованных жидкостях, которая заключается в переориентации молекулы под действием тепловых флуктуаций. При этом молекула преодолевает потенциальный барьер $U_{0}$, сформированный ее ближайшим окружением.

$\beta$-переходу, как известно, предшествует универсальный $\gamma$-процесс [25]: малоугловые крутильные колебания - либрация молекул, которая, как уже отмечалось [1], обусловливает появление полосы Поли в низкочастотных ИК и рамановских спектрах конденсированных сред на частоте $v_{\text {libr. }}$. То есть по низкочастотным ИК и рамановским спектрам можно непосредственно определять как параметры либрационного движения, подготавливающего $\beta$-релаксацию, так и размеры участков полимерной цепи, вовлеченных в это движение при $\beta$-переходе.

Обратимся вновь к рис. 2. Из него видно, что интенсивность низкочастотного крыла либрационной полосы (в области частот, меньших $v_{B P}$ ) растет при повышении температуры. Подобный эффект ранее наблюдался в рамановских спектрах стеклообразных твердых тел $[9,26]$. Согласно этим исследованиям, увеличение интенсивности ниже $v_{B P}$ обусловлено растущим с температурой вкладом $\beta$-процесса. Следовательно, частота перегиба в низкочастотных ИК и рамановских спектрах ПММА соответствует, кроме того, и границе перехода от резонансного типа поглощения к релаксационному, когда число звеньев, вовлеченных в либрационное движение, оказывается достаточным для конформационной перестройки в полимерной цепи.

Таким образом, анализ низкочастотных ИК и рамановских спектров ПММА и его олигомеров показал сле- дующее. Изученная полоса поглощения по механизму Поли характеризует крутильные колебания (либрации) мономерных звеньев этих полимеров, обусловливающие универсальный $\gamma$-процесс $(\delta$-переход в полимерной терминологии). Найденная по частоте перегиба на низкочастотном крыле этой полосы $v_{B P}$ максимальная длина корреляционного участка макромолекулы близка к размеру статистического сегмента, движение которого лежит в основе релаксационного $\beta$-перехода. Частоты ниже частоты бозонного пика $v_{B P}$ соответствуют релаксационной подвижности макромолекул, которая реализуется, когда число монозвеньев, вовлеченных в либрационное движение, становится достаточным для осуществления конформационного перехода в полимерной цепи.

\section{Список литературы}

[1] Bershtein V.A., Ryzhov V.A. // Adv. Polym. Sci. 1994. V. 114. P. 43.

[2] Рыжмов В.А., Берштейн В.А. // ФТТ. 2008. Т. 50. № 10. C. 1901; Ryzhov V.A., Bershtein V.A. // Phys. Solid State. 2008. V. 50. N 10. P 1985.

[3] Рызков B.A. // ФТТ. 2017. Т. 59. № 7. C. 1422; Ryzhov V.A. // Phys. Solid State. 2017. V. 59. N 7. P. 1450.

[4] Shuker R., Gammon R.W. // Phys. Rev. Lett. 1970. V. 25. P. 222.

[5] Bembenek S.D., Laird B.B. // J. Chem. Phys. 2001. V. 114. P. 2340.

[6] Рыжмов В.A. Длинноволновые ИК спектры олигомеров поли- $\alpha$-метилстирола, поликарбоната и полиметилметакрилата // Физико-химия полимеров. Тверь: Твер. гос. ун-т. 2003. B. 9. C. 37.

[7] Смирнов Б.3., Морозова И.С., Марченко А.П. Маркевич М.А., Пущаева Л.М., Ениколопян Р.С. // ДАН СССР 1980. T. 255. C. 608

[8] Рызмов В.А., Тонков М.В. Техника длинноволновой ИК спектроскопии // В сб. Молекулярная спектроскопия. Л.: Изд-во Ленингр. ун-та. 1973. В. 2. С. 108.

[9] Novikov V.N., Sokolov A.P., Stube B., Surovtsev N.V., Duval E., Mermet A. // J. Chem. Phys. 1997. V. 107. P. 1057.

[10] Caliskan G., Kisliuk A., Novikov V.N., Sokolov A.P. // J. Chem. Phys. 2001. V. 114. P. 10189.

[11] Poley J.Ph. // Appl. Sci. Res. Sec. B. 1955. V. 4. P. 337.

[12] Viras J.F., King T.A. // Polymer. 1984. V. 25. P. 899.

[13] Либов В.С., Перова Т.С. Низкочастотная спектроскопия межмолекулярных взаимодействий в конденсированных средах // Тр. ГОИ. СПб.: Тип. ГОИ им. С.И. Вавилова. 1992. T. 81. B. 215. C. 3-193.

[14] Larkin I.W. // J. Chem. Soc. Faraday Trans. II. 1973. V. 69. P. 1278

[15] Evans M.W., Evans G.J., Coffey W.T., Gricolini P. Molecular Dynamics and Theory of Band Spectra. NY: WileyInterscience, $1982.866 \mathrm{p}$.

[16] Рыжсов В.А., Берштейн В.А. // Высокомолекулярные соединения. 1989. Т. 31А. № 3. С. 451.

[17] Бирштейн Т.М., Птищин О.Б. // Конформации молекул. М.: Наука, 1964. С. 65.

[18] Sokolov A.P., Kisliuk A., Soltwisch M., Quitmann D. // Phys. Rev. Lett. 1992. V. 69. P. 1540. 
[19] Берштейн В.А., Егоров В.М. Дифференциальная сканирующая калориметрия в физико-химии полимеров. Л.: Химия, 1990. $255 \mathrm{c}$.

[20] Spells R.J., Shepherd I.W. // J. Chem. Phys. 1977. V. 66. P. 1427.

[21] Buchenau U., Pecharreman C., Zorn R., Frick B. // Phys. Rev. Lett. 1996. V. 77. P. 659.

[22] Bergman R., Svanberg C., Andersson D., Brodin A., Torell L.M. // J. Non-Cryst. Sol. 1998. V. 235-237. P. 225.

[23] Готлиб Ю.Я., Даринский А.А., Светлов Ю.Е. Физическая кинетика макромолекул. Л.: Химия, 1986. 272 с.

[24] Johari G.P., Goldstein M. // J. Chem. Phys. 1971. V. 55. P. 4245.

[25] Reid C.J., Evans M.W. // J. Chem. Phys. 1982. V. 76. P. 2576.

[26] Surovtsev N.V., Wiedersich J.A., Novikov V.N., Rossler E., Sokolov A.P. // Phys. Rev. 1998. B58. P. 14888. 